Revista Brasileira de Agricultura Irrigada v.11, nº.6, p. 1904 - 1913, 2017

ISSN 1982-7679 (On-line)

Fortaleza, CE, INOVAGRI - http://www.inovagri.org.br

DOI: $10.7127 /$ rbai.v11n600650

Protocolo 650.17 - 29/03/2017 Aprovado em 19/05/2017

\title{
CARACTERÍSTICAS BIOQUÍMICAS DO MAMÃO EM FUNÇÃO DA CINZA VEGETAL E COBERTURA MORTA EM CULTIVO AGROECOLÓGICO
}

\author{
Luana Soares da Silva ${ }^{1}$, Bruno Cordeiro de Almeida², Paulo Gleisson Rodrigues de Sousa ${ }^{3}$, \\ Raimundo Nonato Távora Costa ${ }^{4}$, Maria Jayane Mota Bezerra ${ }^{5}$, Denise Vieira Vasconcelos ${ }^{6}$
}

\section{RESUMO}

O mamão é uma cultura com expressiva importância econômica e ampla faixa de cultivo. No sentido de analisar a qualidade da produção de mamão em sistema de produção agroecológico, a presente pesquisa teve como objetivo avaliar os caracteres qualitativos sólidos solúveis totais, acidez total titulável e grau de doçura de frutos de mamoeiro do grupo formosa em uma unidade de experimentação de base familiar submetida aos fatores de produção cinza vegetal e cobertura morta. O delineamento foi em blocos ao acaso com parcelas subdivididas, constituída por quatro tratamentos primários (doses de cinza) 0, 50, 100 e 150\% da quantidade recomendada do fator de produção, dois secundários (sem e com cobertura morta de bagana de carnaúba na razão de $16 \mathrm{t} \mathrm{ha}^{-1}$ ) quatro blocos. As variáveis analisadas foram qualitativas sólidos solúveis totais (SST), acidez total titulável (ATT) e a relação (SST)/(ATT) (Grau de doçura) que lhes conferem qualidades dentro dos padrões para comercialização. Os resultados permitiram as seguintes conclusões: Os frutos de mamoeiro do Grupo Formosa apresentaram valores médios associados às variáveis qualitativas sólidos solúveis totais (SST), acidez total titulável (ATT) e lhes conferem qualidades próximo aos padrões para comercialização no mercado; O grau de doçura dos frutos do mamoeiro medido através da relação SST/ATT conferem valores médios, se considerados todos os tratamentos (primários e secundários) que chegam a ser o dobro do valor médio de referência para frutos do Grupo Formosa; A cultura apresenta um grande potencial para a região e quando bem manejada pode ser explorada nas diversas escalas.

Palavras-chave: Carica Papaya, Agricultura Familiar, Cobertura Morta.

\footnotetext{
${ }^{1}$ Eng. Agrônoma, Mestranda em Engenharia Agrícola, Universidade Federal do Ceará, Fortaleza, Ceará, Brasil, e-mail: luanasa19@hotmail.com

${ }^{2}$ Eng. Agrônomo, Universidade Federal do Ceará, Fortaleza, Ceará, Brasil, e-mail: edaphos@hotmail.com

${ }^{3}$ Eng. Agrônomo, Mestrando em Engenharia Agrícola, Universidade Federal do Ceará, Fortaleza, Ceará, Brasil, email: paulo.ufc.agro@gmail.com

${ }^{4}$ Eng. Agrônomo, Professor Titular, Adjunto IV, do curso de Agronomia da Universidade Federal do Ceará, Fortaleza, Ceará, Brasil, e-mail: rntcosta@ufc.br

${ }^{5}$ Eng. Agrônoma, Mestre em Agronomia/Fitotecnia, Universidade Federal do Ceará, Fortaleza, Ceará, Brasil, e-mail: Jayanemota@alu.ufc.br

${ }^{6}$ Eng. Agrônoma, Professora de Engenharia Agrícola do Instituto Federal do Pará, Bragança, Pará, Brasil, e-mail: denisevascocelos@hotmail.com
} 


\title{
BIOCHEMICAL CHARACTERISTICS OF MAMMON IN FUNCTION OF VEGETABLE GRAY AND DEAD COVERAGE IN AGROECOLOGICAL CULTIVATION
}

\begin{abstract}
Papaya is a crop with significant economic importance and wide range of cultivation. In order to analyze the quality of papaya production in an agroecological production system, the present study had the objective of evaluating the qualitative total soluble solids, titratable total acidity and degree of sweetness of papaya fruits of the formosa group in an experimentation unit Based on the factors of production gray plant and mulch. The experimental design was in randomized blocks with subdivided plots, consisting of four primary treatments (gray doses) 0, 50, 100 and $150 \%$ of the recommended amount of the production factor, two secondary treatments (without and with mulch of carnauba bagana In the ratio of $16 \mathrm{t}$ ha-1) four blocks. The variables analyzed were qualitative total soluble solids (TSS), total titratable acidity (TSS) and the ratio (SST/ATT) (degree of sweetness) that confer them qualities within the standards for commercialization. The results allowed the following conclusions: The fruits of papaya fruit of the Formosa Group presented mean values associated to the total soluble solid qualitative variables (TSS), total titratable acidity (ATT) and confer them qualities close to the standards for commercialization in the market; The degree of sweetness of the papaya fruits measured through the TSS / ATT ratio gives mean values, considering all treatments (primary and secondary) that are twice the average reference value for fruits of the Formosa Group; The culture has great potential for the region and when well managed can be explored at different scales.
\end{abstract}

Keywords: Papaya, Family farming, Mulch, Fruit-quality.

\section{INTRODUÇÃO}

O mamoeiro pertence à classe Dicotyledoneae, subclasse Archichlamydeae, ordem Violales, subordem Caricaceae, família Caricaceae e gênero Carica. É uma planta herbácea com caule verde podendo chegar até oito metros de altura, com vida útil comercial de até quatro anos (SIMÃO, 1998). Em virtude de sua expressiva importância econômica e ampla faixa de cultivo, tem sido objeto de estudo em diversos trabalhos de pesquisa, principalmente, aqueles relacionados a estudos para otimização de índices de produtividade desta cultura (MARINHO et al., 2008; FONTES et al., 2010; MORAIS et al., 2015).

No entanto a transição agroecologia vai além do aspecto da produção sem uso de agrotóxico, mas a principio, traz ao produtor um principio que oportuniza o produtor $o$ acesso a um modelo de agricultura, onde seja aproveitado no máximo os recursos presentes na propriedade e assim, o produtor passe identificar alternativas para obter bons resultados de produção e essa atendendo os critérios de qualidade para o mercado, respeitando os limites ambientais, econômicos e sociais (CAPORAL et al., 2006; CAPORAL, 2009; SILVA, 2010).

A utilização de fontes alternativas para adubação é importante para se reduzir os custos, aumentarem a sustentabilidade e a preservação de recursos naturais, sendo uma das principais vantagens desta adubação, a melhoria de aspectos físicos e químicos do solo (PIVA et.al, 2014). No entanto, fontes alternativas de fertilizantes pode ser uma forma de substituição de adubos químicos sintéticos. A cinza constitui-se como uma delas, com origem em geral da queima da madeira, podendo conter elevados teores de K, P, Ca e Mg. (NKANA et al, 1998; SOFIATTI, 2007).

No sentido de analisar a qualidade da produção de mamão em sistema de produção agroecológico, a presente pesquisa teve como objetivo avaliar os caracteres qualitativos sólidos solúveis totais, acidez total titulável e 
grau de doçura de frutos de mamoeiro do grupo formosa em uma unidade de experimentação de base familiar submetida aos fatores de produção cinza vegetal e cobertura morta.

\section{MATERIAL E MÉTODOS}

O experimento foi conduzido à jusante do açude Pereira de Miranda, em área pertencente ao Departamento Nacional de Obras Contra as Secas - DNOCS, município de Pentecoste, Ceará, no período de janeiro de 2014 a fevereiro 2015.

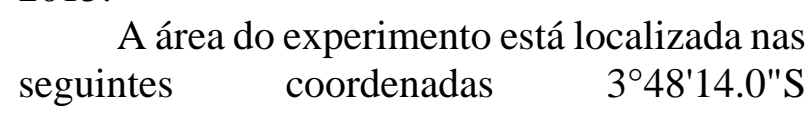

39¹5'51.7"W e altitude de $25 \mathrm{~m}$. O clima da região é semiárido, seco, existindo uma pequena temporada úmida, a qual permite o desenvolvimento da vegetação rasteira (Embrapa, 1999).

Os atributos físicos e químicos do solo na camada de $0-0,2 \mathrm{~m}$ são apresentados na (Tabela 1). Trata-se de um solo de textura franco arenosa sem problemas de salinidade e sodicidade, sendo que na faixa de tensões entre 33 e $1500 \mathrm{kPa}$ armazena 15,6 $\mathrm{mm}$ nos primeiros $0,20 \mathrm{~m}$ de solo, valor este que supera os requerimentos diários correspondentes às lâminas de irrigação nos meses mais críticos de demanda de água.

Tabela1. Atributos físicos e químicos do solo na camada arável ( 0 - 0,2 m).

\begin{tabular}{lclc}
\hline Atributos químicos & $(0-0,20 \mathrm{~m})$ & Atributos físicos & $(0-0,20 \mathrm{~m})$ \\
\hline $\mathrm{P}_{2} \mathrm{O}_{5}\left(\mathrm{mg} \mathrm{kg}^{-1}\right)$ & 37,00 & Areia fina $\left(\mathrm{g} \mathrm{kg}^{-1}\right)$ & 706,00 \\
$\mathrm{~K}^{+}\left(\mathrm{cmol}_{\mathrm{c} \mathrm{kg}}\right)$ & 0,32 & Areia grossa $\left(\mathrm{g} \mathrm{kg}^{-1}\right)$ & 40,00 \\
$\mathrm{Na}^{+}\left(\mathrm{cmol}_{\mathrm{c}} \mathrm{kg}^{-1}\right)$ & 0,13 & Silte $\left(\mathrm{g} \mathrm{kg}^{-1}\right)$ & 75,00 \\
$\mathrm{Ca}^{2+}\left(\mathrm{cmol}_{\mathrm{c}} \mathrm{kg}^{-1}\right)$ & 2,50 & Argila $\left(\mathrm{g} \mathrm{kg}^{-1}\right)$ & 39,00 \\
$\mathrm{Mg}^{2+}\left(\mathrm{cmol}_{\mathrm{c}} \mathrm{kg}^{-1}\right)$ & 2,50 & Argila natural $\left(\mathrm{g} \mathrm{kg}^{-1}\right)$ & 39,00 \\
$\mathrm{Al}^{3+}\left(\mathrm{cmol}_{\mathrm{c}} \mathrm{kg}^{-1}\right)$ & 0,10 & Densidade solo $\left(\mathrm{g} \mathrm{cm}^{-3}\right)$ & 1,62 \\
$\mathrm{M} . \mathrm{O} .\left(\mathrm{g} \mathrm{kg}^{-1}\right)$ & 7,97 & Densidade partículas $\left(\mathrm{g} \mathrm{cm}^{-3}\right)$ & 2,64 \\
$\mathrm{C} / \mathrm{N}$ & 10,00 & Floculação $\left(\mathrm{g} 100 \mathrm{~g}^{-1}\right)$ & 51,00 \\
$\mathrm{pH}$ & 6,00 & Classe textural & Franco arenosa \\
$\mathrm{CE}(\mathrm{dS} \mathrm{m}$ & $-1)$ & Umidade0,03 MPa & 9,57 \\
PST & 0,20 & Umidade a $1,50 \mathrm{MPa}$ & 4,74 \\
\hline
\end{tabular}

Fonte: Laboratório de Solos e Água da Universidade Federal do Ceará (2014).

Os tratamentos primários (C1, C2 e C3) constituíram-se, respectivamente, das aplicações correspondentes a 50, 100 e 150\% da quantidade de cinza vegetal recomendada, conforme manual de recomendações de adubação para o Estado de Pernambuco 2008 ( $2^{\circ}$ aproximação), para aplicação no cultivo de mamoeiro, além de um tratamento testemunha, C0 (sem aplicação de cinza vegetal). Vale ressaltar que a definição da quantidade de cinza a ser aplicada foi definida com base na quantidade de potássio exigida pela cultura. Empregou-se $587 \mathrm{~g}$ de $\mathrm{Ca}^{2+}$ por planta, muito além do necessário, juntamente com 55 g de $\mathrm{Mg}^{2+}$. Quanto ao teor de nitrogênio e fósforo, foram 129,87 e $50 \mathrm{~g}$ por planta de maneira respectivamente, que estes ficaram em déficit quanto à proporção sugerida.

A dose de cinza correspondente a $100 \%$ da necessidade foi de $80 \mathrm{~g}$ de $\mathrm{K}_{2} \mathrm{O}$ por planta, representando um total de $1.195 \mathrm{~g}$ de cinza vegetal no primeiro ciclo de produção a aplicação foi fracionada em cinco parcelas.

$\mathrm{O}$ delineamento experimental foi em blocos ao acaso com parcelas subdivididas, constando de quatro tratamentos primários, dois secundários e quatro blocos. Os tratamentos primários constaram dos níveis correspondentes a 0, 50, 100 e $150 \%$ da quantidade de cinza vegetal recomendada, sendo a mesma produzida em forno de padaria. Como fator secundário utilizou-se bagana de 
carnaúba, sendo um tratamento constituído pela aplicação de $16 \mathrm{t} \mathrm{ha}^{-1}$ (B1) e um tratamento testemunha (sem aplicação de bagana de carnaúba - B0).

Antes do estabelecimento da cultura do mamoeiro no campo realizou-se a semeadura das leguminosas Calopogonium mucunoides e Pueraria phaseoloides com vistas à sua incorporação e, portanto, a uma maior disponibilidade de nutrientes, sobretudo nitrogênio.

A cultura do mamoeiro, cultivar (Tainung 01) do grupo Formosa foi semeada em bandejas de polietileno preta de 168 células no dia 08 de junho de 2014, utilizando-se uma mistura de argila, areia e esterco curtido de bovino na proporção 1:1:1. A germinação ocorreu entre 09 e 12 dias após a semeadura.

As covas no espaçamento de 2,5 m x 2,5 $\mathrm{m}$ foram preparadas manualmente nas dimensões de $0,40 \mathrm{~m} \times 0,40 \mathrm{~m} \times 0,40 \mathrm{~m}$ e preenchidas com $32 \mathrm{~L}$ de esterco curtido de bovino e ovino e a mesma quantidade com solo da parte superficial retirado das próprias covas. As características químicas do material utilizado na cova em proporção de $50 \%$ esterco curtido e $50 \%$ de solo da camada superficial da cova estão contidas na Tabela 2.

Tabela 2. Características químicas do material utilizado na adubação de fundação.

\begin{tabular}{lllllllllll}
\hline \multicolumn{1}{c}{$\left(\mathrm{g} \mathrm{kg}^{-1}\right)$} & \multicolumn{5}{c}{$\left(\mathrm{mg} \mathrm{kg}^{-1}\right)$} \\
\hline $\mathrm{N}$ & $\mathrm{P}$ & $\mathrm{P}_{2} \mathrm{O}_{5}$ & $\mathrm{~K}$ & $\mathrm{~K}_{2} \mathrm{O}$ & $\mathrm{Ca}$ & $\mathrm{Mg}$ & $\mathrm{Fe}$ & $\mathrm{Cu}$ & $\mathrm{Zn}$ & $\mathrm{Mn}$ \\
\hline 3,7 & 1,4 & 3,2 & 3,6 & 4,4 & 6,9 & 6,0 & - & 14,1 & 56,4 & 208,6 \\
\hline
\end{tabular}

Fonte: Laboratório de Solos e Água da Universidade Federal do Ceará (2014).

O plantio definitivo em covas ocorreu no dia 03 de julho de 2014, ou seja, 25 dias após a semeadura, quando as mudas estavam com seis folhas definitivas. Neste período e durante dois dias, as plantas receberam exposição total ao sol para fins de adaptação. O replantio "reposição de plantas que não vingaram” se deu seis dias após o plantio.

Semanalmente foram realizados tratos culturais, tais como retirada das plantas invasoras de forma manual na projeção da copa com enxada, entre plantas e linhas. Quarenta dias após o plantio, aplicou-se a primeira adubação com cinza vegetal e a cobertura morta com bagana de carnaúba.

Utilizou-se um sistema de irrigação localizada do tipo microaspersão com um emissor para duas plantas operando a uma vazão de $112 \mathrm{~L} \mathrm{~h}^{-1}$ para uma pressão de serviço 15 mca, cuja linha principal era de tubos de PVC (diâmetro nominal de $50 \mathrm{~mm}$ ), com linhas laterais constituídas por mangueiras de polietileno (diâmetro nominal de $16 \mathrm{~mm}$ ). A fonte de água é oriunda de um pequeno córrego reabastecido por fluxo subterrâneo procedente do açude Pereira de Miranda, localizado próximo à área do experimento, cuja classificação é C3S1, conforme Ayers e Westcot (1999). Constitui, portanto uma qualidade de água que não deve ser usada em solos com drenagem deficiente e mesmo com drenagem adequada deve ser utilizada em tolerantes aos sais, utilizando-se irrigação localizada e com critério de manejo adequado.

O requerimento de água da cultura foi calculado para os diferentes meses e estádios da cultura conforme a Equação 1:

$$
\mathrm{Ti}=\frac{\text { ETo. Kc. Ap }}{\text { N.qe }}
$$

em que:Ti: tempo de irrigação, h; ETo: evapotranspiração de referência diária, mm; Kc: coeficiente de cultivo da cultura; Ap: área útil por planta, $\mathrm{m}^{2}$; qe: vazão do emissor, $\mathrm{L}$ $\mathrm{h}^{-1}$; N: número de emissores por planta.

A evapotranspiração de referência (ETo) foi calculada através do método de PenmanMonteih (ALLEN; PRUITT,1991). Utilizando o software Cropwat com os dados de entrada para o cálculo de ETo foram obtidos de uma série histórica para o município de Pentecoste relativa ao período 1970-1998.

Já os coeficientes de cultivo nos diversos estádios fenológicos foram obtidos por Montenegro et al., (2004), conforme a Tabela 3. 
Tabela 3. Coeficientes de cultivo do mamoeiro nos diferentes estádios fenológicos.

\begin{tabular}{llll}
\hline \multicolumn{1}{c}{ Dias após a semeadura } & \multicolumn{1}{c}{ Estádios } & Kc \\
\hline $84-107$ & Vegetativo & 0,6 & \\
$115-260$ & Floração/Frutificação & 1,0 & \\
$267-380$ & Floração/Frutificação/Maturação & 0,8 & \\
\hline
\end{tabular}

Fonte: Montenegro, et al., (2004).

No oitavo mês após o plantio os frutos começaram a ser colhidos, sendo que no décimo mês e no segundo estágio de maturação, os mesmos foram colhidos para fins de análises das variáveis sólidos solúveis totais e acidez titulável, junto ao Laboratório de Frutos Tropicais da Universidade Federal do Ceará.

A amostragem dos frutos foi feita com um fruto por subparcela, quatro por cada tratamento em um total de oito, totalizando 32 frutos analisados sendo que os frutos eram colhidos no segundo estágio de maturação levados ao laboratório e no dia seguinte todos os frutos eram analisados.

$\mathrm{Na}$ determinação de sólidos solúveis totais (SST), retirou-se uma amostra da polpa de cada repetição em um total de quatro, que foi processada em um mixer, modelo RI 6720 marca Philips-Walita, sendo o suco resultante avaliado em refratômetro digital modelo Pocket PAL - 1 (Attago , Ltd, Japan), com escala variando de 0 até $53 \%$ ( ${ }^{\circ}$ Brix) e compensação automática de temperatura.

A acidez total titulável (ATT) foi determinada por triplicata utilizando-se 5,0 g de cada uma das quatro amostra por tratamento e adicionando-se $50 \mathrm{~mL}$ de água destilada e em seguida homogeneizada. $\mathrm{Na}$ sequencia, colocava-se a mistura em um Erlenmeyer adicionando-se três gotas de fenolftaleína alcoólica $1 \%$ e titulando-se com solução de $\mathrm{NaOH} 0,1 \mathrm{~N}$ previamente padronizada, até atingir o ponto de viragem, o qual era caracterizado pelo surgimento da cor rosada persistente. Os resultados foram expressos em porcentagem de ácido cítrico (ZENEBON, et al., 2008).
Para a determinação do cálculo de percentagem de acidez utilizou-se a equação 2 :

$$
\operatorname{Acidez}(\%)=\frac{F_{\text {ácido }} \times 10 \times F_{\mathrm{NaOH}} \times V_{\mathrm{NaOH}}}{M} \quad 2
$$

F ácido : Fator de correção obtido na padronização do ácido cítrico

$\mathrm{F} \mathrm{NaOH}$ : Fator de correção obtido na padronização do $\mathrm{NaOH}$

$\mathrm{V}_{\mathrm{NaOH}}$ : Volume gasto na titulação da amostra $(\mathrm{mL})$

M: massa de polpa (g).

A relação SST/ATT baseia-se no cálculo do SST ( ${ }^{\circ}$ Brix)/(ATT) acidez total titulável, sendo expressa em ácido orgânico predominante no fruto, o qual mede o grau de doçura do fruto.

As análises estatísticas das variáveis foram analisadas utilizando-se o software Assistat 7.7 (SILVA; AZEVEDO, 2016) e Excel. Na análise da variância, os tratamentos foram comparados pelo teste $F$, sendo considerado um nível mínimo de significância de 5\% de probabilidade. As comparações entre médias para o tratamento secundário foram realizadas pelo teste de Tukey em níveis de 5\% e $1 \%$ de probabilidade.

\section{RESULTADOS E DISCUSSÃO}

Os dados de sólidos solúveis totais ( ${ }^{\circ}$ Brix) - (SST), acidez total titulável - (ATT) e relação SST/ATT referente aos tratamentos analisados foram aglutinados na Tabela 4.

Tabela 4. Resumo da ANOVA para (SST), (ATT) e (SST/ATT) em função das lâminas de irrigação e cobertura com bagana de carnaúba. Umirim - CE. 2016.

\begin{tabular}{|c|c|c|c|c|}
\hline \multirow{2}{*}{ Fonte de variação } & \multirow{2}{*}{ GL } & \multicolumn{3}{|c|}{ Quadrado médio } \\
\hline & & SST & ATT\% & SST/ATT \\
\hline Bloco & 3 & $0,36184^{\mathrm{ns}}$ & $0,00002^{n}$ & $420,04365^{\mathrm{ns}}$ \\
\hline
\end{tabular}


Silva et al.

$\begin{array}{lcccr}\text { Cinza (C) } & 3 & 0,10847^{\mathrm{ns}} & 0,00003^{\mathrm{ns}} & 337,67031^{\mathrm{ns}} \\ \text { Resíduo (C) } & 9 & 0,136644^{\mathrm{ns}} & 0,00011^{\mathrm{ns}} & 1127,56948 \\ \text { Cobertura Morta (CM) } & 1 & 0,03850^{\mathrm{ns}} & 0,00003{ }^{\mathrm{ns}} & 237,07531^{\mathrm{ns}} \\ \text { C x CM } & 3 & 0,10585^{\mathrm{ns}} & 0,00007 \mathrm{~ns}^{\mathrm{ns}} & 474,05615^{\mathrm{ns}} \\ \text { Resíduo (CM) } & 12 & 0,27431 & 0,00008 & 659,05010 \\ \text { CV (C) } & (\%) & 3,53 & 19,30 & 17,20 \\ \text { CV (CM) } & (\%) & 5,00 & 16,80 & 13,15\end{array}$

(**) Efeito significativo a 0,01 e $\left({ }^{*}\right)$ a 0,05 de probabilidade; $\left({ }^{\text {ns }}\right)$ não significativo a nível de 0,05 de probabilidade pelo teste F.

Pelos resultados da análise de variância, foi observado que não ocorreu interação entre os fatores cinza x cobertura morta (C x CM) nem tampouco efeito significativo em relação aos níveis cinza e cobertura morta nas variáveis analisadas pelo teste $\mathrm{F}$ de probabilidade ao nível de significância de 5\%.

Conforme pode-se contatar pela Figura 1, os resultados de SST obtidos nesta pesquisa encontram-se um pouco a baixo da faixa de valores de referência de Brasil, (1994) estabelecendo que o mínimo seria de $11,5 \%$ de sólidos solúveis para que os frutos de mamão sejam bem aceitos pelos consumidores. Sendo que a maior média obtida foi de 10,68 ( ${ }^{\circ}$ Brix) para o tratamento C2B1, o qual corresponde a aplicação de 1.195,00 g de cinza por planta e cobertura com bagana de carnauba.

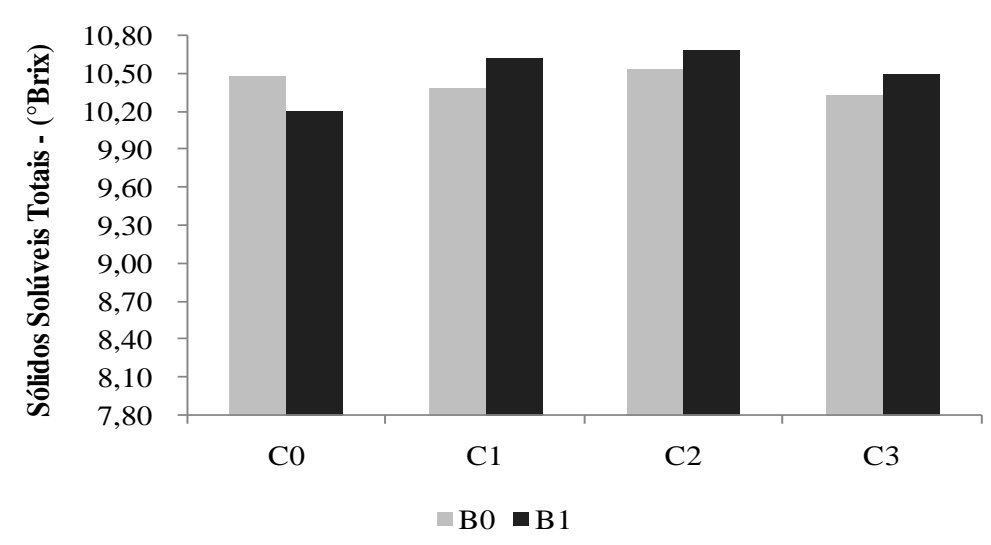

Figura 1. Solido Solúveis Totais em função dos fatores cinza e bagana.

Rodolfo Júnior et al., (2007) demonstraram para o Grupo Formosa, valores de (SST) $14^{\circ}$ Brix e o mesmo acontecendo com os frutos da cultivar Sunrise Solo, mantendo o teor de SST constante em $11^{\circ}$ Brix. Souza (2004) obteve valores médios de SST para a cultivar Tainung 01 da ordem de 10,5 e 12,8 \% no segundo estágio de maturação, resultado que colabora com os obtidos nesta pesquisa.

Morais et al., (2007) afirma que teores de sólidos solúveis, não foram estatisticamente significativo, e os valores médios obtidos foram 13,65 ํㅜㄹ para sólidos solúveis.
Os valores médios de SST demonstram que os tratamentos com aplicação de cinza e presença da cobertura morta incrementa os valores de SST nos frutos do mamoeiro. Resultados semelhantes foram obtidos por Sousa et al., (2017) ao analisar variáveis quantitativas do mamoeiro nesta mesma unidade de experimentação.

Os valores médios de Acidez Total Titulável (ATT) de frutos do mamoeiro em função dos tratamentos cinza e bagana de carnaúba podem ser constados na Figura 2. 


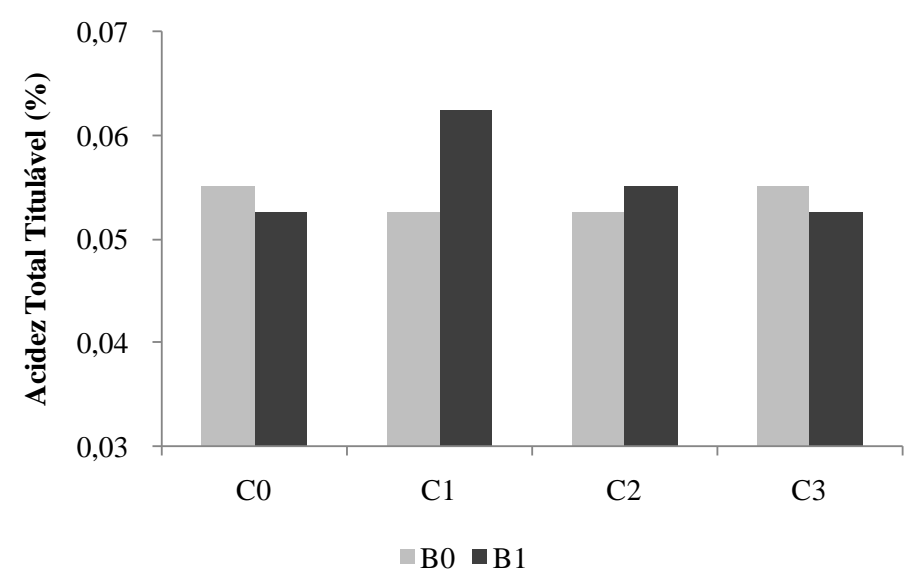

Figura 2. Acidez Total Titulável (ATT) em função dos fatores cinza e cobertura morta com bagana.

Os valores médios de ATT da poupa dos frutos analisados variaram entre 0,04 e $0,08 \%$ sendo, portanto considerada uma acidez baixa. Verificaram-se ainda baixas variações entre os tratamentos, não obstante estes valores se situarem abaixo dos valores de referência.

Valores esses que são inferiores aos de Souza (2004), o qual em estudo com mamão formosa verificou valores de ATT entre 0,16 e $0,17 \%$ no segundo estágio de maturação. Sendo que se encontrou na faixa dos valores encontrados por Fagundes e Yamanishi (2001), onde os mesmos constataram AT dos frutos entre 0,04 e 0,16\% de ácido cítrico. E valores superiores foram contatados por Rodolfo Júnior et at., (2007) para a cultivar Formosa com valores médios de $0,11 \%$, e os da cultivar $S$. Solo apresentou valor médio de $0,08 \%$.

Na Figura 3 estão apresentados os valores médios de relação SST/ATT de frutos do mamoeiro em função dos tratamentos cinza e bagana de carnaúba. Os dados demonstram que os valores médios da relação SST/ATT variaram entre 173,49 e 201,87 respectivamente para os tratamentos C1B1, equivalente a aplicação de 599,00 g de cinza por planta e presença de bagana e o tratamento C0B0, sem cinza e sem bagana.

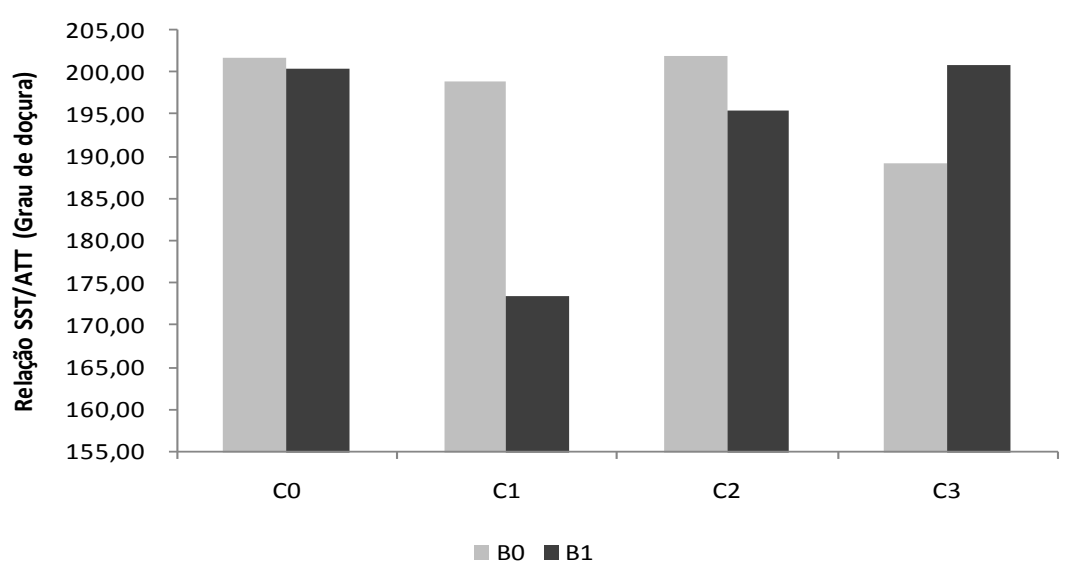

Figura 3. Valores da Relação SST/ATT (Grau de doçura) em função dos fatores cinza e bagana.

Não obstante, estes valores se situam bem acima de alguns estudos com o mamoeiro do Grupo Formosa, tais como o desenvolvido por Rodolfo Júnior et al. (2007) que obtiveram valores médios da ordem de 100,10. Sendo esse resultado em função do comportamento do SST esta muito próximo da faixa de aceitação e ATT muito abaixo, o que vai tornar esses valores acima da faixa de normalidade.

Conforme destacado anteriormente, Sousa et al., (2017) analisando variáveis associadas à produtividade física e 
produtividade da água nesta mesma unidade de experimentação, obteve resultados altamente significativos para o fator de produção bagana de carnaúba. A princípio causa estranheza o fato da não observância de níveis significativos de probabilidade relativos à rejeição da hipótese de nulidade na análise de variáveis qualitativas dos frutos do mamoeiro, conforme se observa neste estudo. Não obstante, estas variáveis qualitativas são influenciadas por fatores como condições edafoclimáticas, variedade, época e local de colheita, tratos culturais e manuseio pós-colheita, conforme Fagundes e Yamanishi (2001).

Estes resultados podem ter ocorrido tanto pelo fato da planta não sofreu estresse neste sistema ou por estás variáveis analisadas serem ligadas a uma característica genética da própria cultivar onde o genes que comanda está função não é facilmente alterado pelos fatores climáticos somente se tivesse ocorrido um estresse muito grande como por exemplo estresse hídrico, dano mecânico ou a falta de algum nutriente onde a planta não conseguiria completar seu ciclo biológico.

\section{CONCLUSÕES}

Os frutos de mamoeiro do Grupo Formosa apresentaram valores médios associados às variáveis qualitativas sólidos solúveis totais (SST), acidez total titulável (ATT) e lhes conferem qualidades próximo aos padrões para comercialização no mercado;

O grau de doçura dos frutos do mamoeiro medido através da relação SST/ATT conferem valores médios, se considerados todos os tratamentos (primários e secundários) que chegam a ser o dobro do valor médio de referência para frutos do Grupo Formosa;

Pelos resultados qualitativos apresentados, pode-se perceber que essa cultura apresenta um grande potencial para a região e a mesma quando bem manejada pode ser explorada nas diversas escalar, com destaque ao pequeno produtor.

\section{REFERÊNCIAS BIBLIOGRÁFICAS}

ALLEN, R. G.; PRUITT, W. O. FAO - 24 Reference Evapotranspiration Factors. Journal of irrigation and drainage engineering, 1991.

AYERS, R. S.; WESTCOT. D. W. A qualidade da água na agricultura. Tradução de GHEYI, H. J.; MEDEIROS, J. F. de; DAMASCENO, F. A. V. Campina Grande: UFPB, 1999. (Estudos FAO: Irrigação e Drenagem, 29 Revisado I). Título original: Water Quality for Agriculture.

BRASIL. Ministério da Agricultura, do Abastecimento e da Reforma Agrária - SDR FRUPEX. Mamão para exportação: Aspectos Técnicos da Produção. EMBRAPA, Brasília DF, 52p, (1994).

CAPORAL, F. R. Agroecologia: uma nova ciência para apoiar a transição a agriculturas mais sustentáveis. Brasília: Ministério do Desenvolvimento Agrário. 2009. 30p.

CAPORAL, F. R.; COSTABEBER, J. A.; PAULUS, G. Agroecologia: matriz disciplinar para ou novo paradigma para o desenvolvimento rural sustentável. In: TOMMASINO, H; HEGEDUS, P. (Ed.). Extensión: reflexiones para la intervención en el medio urbano y rural. UFSM / Universidad de La República, 2006.

FAGUNDES, G.; YAMANISHI, O. K. Características físicas e químicas de frutos de mamoeiro do grupo ‘solo' comercializados em 4 estabelecimentos De brasília-DF. Revista Brasileira de Fruticultura. v. 23, n. 3, p. 541545, 2001.

FONTES, R. V.; VIANA, A. P.; PEREIRA, M. G.; OLIVEIRA, J. G. de.; SILVA, D. M.; BROETTO, S. G.; SILVA, M. M. Diferentes espaçamentos de plantio e níveis de adubação sobre a atividade da redutase do nitrato em folhas do híbrido de mamoeiro UENF/CALIMAN-01. Revista Brasileira Fruticultura, v. 32, n. 4, p. 1138 - 1145, 2010. 
MARINHO, A. B.; BERNARDO, S.; SOUSA, E. F.; PEREIRA, M. G.; MONNERAT, P. H. Produtividade e qualidade de frutos de mamão cultivar 'golden' sob diferentes lâminas de irrigação e doses de potássio no norte de Espírito Santo. Engenharia Agrícola, v. 28, n. 3, p. 417-426, 2008.

MONTENEGRO, A. A. T.; BEZERRA, F. M. L.; LIMA, R. N. Evapotranspiração e coeficientes de cultura do mamoeiro para a região litorânea do Ceará. Engenharia Agrícola, v. 24, n. 2, p. 464-472, 2004.

MORAIS, E. R. C.; MAIA, C. E.; GAUDÊNCIO, H. R. S. C.; SOUSA, D. M. M. Indicadores da qualidade química do solo em áreas cultivadas com mamoeiro irrigado. Revista brasileira de engenharia agrícola e ambiental. v. 19, n. 6, p. 587-591, 2015.

MORAIS. P, L, D, de.; SILVA, G. G. da.; MENEZES, J. B.; NOGUEIRA, F. E. M.; DANTAS, D. J.; SALES JÚNIOR. R. Póscolheita de mamão híbrido uenf/caliman 01 cultivado no rio grande do norte. Revista Brasileira de Fruticultura. v. 29, n. 3, p. 666670, 2007.

NKANA, J. C. V.; DEMEYER, A.; VERLOO, M. G. Efeitos químicos das cinzas de madeira no crescimento da planta em solos ácidos tropicais. Bioresource Technology. v. 63, n. 3, p. 251-260, 1998.

PIVA, R.; BOTELHO, R. V.; MÜLLER, M. M. L.; AYUB, R. A.; ROMBOLÀ, A. D. Adubação de manutenção em videiras cV. Bordô utilizando-se cinzas vegetais e esterco bovino em sistema orgânico. Revista Brasileira Ciências Agrárias. v. 9, n. 2, p. 219-224, 2014.

RODOLFO JÚNIOR, F.; TORRES, L. B. de V.; CAMPOS, V. B.; LIMA, A. R. de.; OLIVEIRA, A. D. de.; MOTA, J. K. de M. Caracterização físico-química de frutos de mamoeiro comercializados na empasa de campina grande-PB. Revista Brasileira de
Produtos Agroindustriais, v. 9, n. 1, p. 53-58, 2007.

SILVA, D. A. da. O perfil do consumidor da feira de transição agroecológica do bairro Valentina Figueiredo, na cidade de João Pessoa - PB. Revista Espaço Acadêmico. v. 9, n. 107, p. 124-128, 2010.

SILVA, F. de A. S.; AZEVEDO, C. A. V. The Assistat Software Version 7.7 and its use in the analysis of experimental data. African Journal of Agricultural Research, v. 11, n. 39, p. 3733-3740, 2016.

SIMÃO, S. Tratado de fruticultura. Piracicaba: FEALQ, 1998. 760p.

SOFIATTI, V.; LIMA, R. de L. S. de.; GOLDFARB, M.; BELTRÃO, N. E. de M. Cinza de madeira e lodo de esgoto como fonte de nutrientes para o crescimento do algodoeiro. Revista de Biologia e Ciências da Terra, v. 7, n. 1, p. 144-152, 2007.

SOUSA, P. G. R. de.; SOUSA, J. de P. F. de.; SOUSA, A. M. de.; COSTA, R. N. T. Produtividade do mamoeiro cultivado sob aplicação de cinzas vegetais e bagana de carnaúba. Revista Brasileira de Agricultura Irrigada. v. 11, n. 1, p. 1201-1212, 2017.

SOUZA, L. M. de. Algumas características físicas e químicas de mamões (Carica papaya L.) dos grupos "formosa" (Tainung 01) e "SOLO" (Golden), com e sem mancha fisiológica, colhidos em diferentes estádios de maturação. Dissertação (Mestrado) Universidade Estadual do Norte Fluminense, Campos dos Goytacazes - RJ, 82p. 2004.

TRINDADE, A. V. Mamão. Produção: aspectos técnicos. Embrapa Mandioca e Fruticultura (Cruz das Almas, BA). — Brasília: Embrapa Comunicação para Transferência de Tecnologia, 2000. 
ZENEBON, O.; PASCUET, N. S.; TIGLEA, P. Métodos Físico-Químicos para Análise de
Alimentos - $4^{\mathrm{a}}$ Edição, Instituto Adolfo Lutz. 2008. 